\title{
Neonatal Sepsis Risk Factors in Public Hospitals in Wollega Zones, Ethiopia
}

\author{
Werku Etafa $^{1 \uparrow} \quad$ Reta Tsegaye $^{2} \quad$ Bizuneh Wakuma $^{1 \uparrow} \quad$ Getahun Fetensa $^{2} \quad$ Vasantha Kumarai $^{1}$ \\ Getu Bayisa $^{3, \# a} \quad$ Feyissa Lemessa ${ }^{4}$ \\ 1.Department of Pediatrics and Neonatal Health Nursing, Institute of Health Science, Wollega University, \\ Nekemte, Ethiopia \\ 2.Department of Nursing, Institute of Health Science, Wollega University, Nekemte, Ethiopia \\ 3.Department of Pharmacy, Institute of Health Science, Wollega University, Nekemte, Ethiopia \\ \#a.Current Address: School of Pharmacy College of Health Science, Addis Ababa University, Addis Ababa, \\ Ethiopia \\ 4.Department of Nursing, St. Paul's Hospital Millennium Medical College, Addis Ababa, Ethiopia
}

"These authors contributed equally to this work.

\section{Abstract \\ Background}

Globally, neonatal death accounts for almost half of the under-five children's mortality rate. In Ethiopia, neonatal sepsis is among the leading causes of neonatal morbidity and mortality. Several studies had assessed the prevalence and associated factors of neonatal sepsis in Ethiopia. However, limited studies examined the risk factors of neonatal sepsis. Thus, this study aimed to assess risk factors for neonatal sepsis among neonates admitted to the neonatal intensive care unit of the selected public hospitals in Wollega Zones.

\section{Methods}

A hospital-based unmatched case-control study was conducted in public hospitals in Wollega zones among 300 newborns admitted to neonatal intensive care units with their index mothers. Neonatal sepsis was diagnosed by a physician based on hematologic records and newborn danger signs. Neonates who were diagnosed for neonatal sepsis were recorded to cases; meanwhile, controls were who had not had sepsis. The consecutive sampling technique was employed to collect data from the study subjects using a 1:1 ratio for cases and controls. The data were entered into Epi Data version 3.1 and exported to SPSS version 20 for analysis. The binary logistic regression model was used to examine the association between dependent and independent variables. Variables were considered as an independent risk factor of neonatal sepsis if the p-value is $<0.05$ in stepwise backward analysis in multivariable logistic regression.

\section{Findings}

Three hundred neonates with their index mothers (150 cases and 150 controls) were included in this study. Multivariable logistic regression analysis showed that mothers who had experienced premature rupture of the membrane $[\mathrm{AOR}=2.94,95 \% \mathrm{CI}(1.39-6.06)]$, mothers who had a history of UTI/STI $[\mathrm{AOR}=2.11,95 \% \mathrm{CI}(1.06-$ 4.19)], neonates' who had APGAR scores of $<7$ at the fifth minute [AOR $=3.69,95 \% \mathrm{CI}(2.08-6.53)]$ and neonates who was resuscitated at birth $[\mathrm{AOR}=2.93,95 \% \mathrm{CI}(1.67-5.14)]$ were the independent risk factors of neonatal sepsis to neonates admitted to neonatal intensive care units.

\section{Conclusions}

This study highlights both maternal and neonatal factors contributing to neonatal sepsis. Maternal counseling, early identification and prompt management of maternal urinary tract infections/sexually transmitted infections during antenatal care service should be emphasized. Also, enhancing safe neonatal resuscitation and infection prevention practice of delivery unit staff through provision of refreshment course.

DOI: $10.7176 / \mathrm{JHMN} / 87-02$

Publication date:March $31^{\text {st }} 2021$

\section{Introduction}

Neonatal sepsis is defined as a clinical syndrome of bacteremia with systemic signs and symptoms of infection in the first four weeks of life (1). It is categorized into early and late-onset neonatal sepsis. Early-onset neonatal sepsis (EONS) is defined as the onset of symptoms before 7 days of life, although some experts limit it to 72 hours of life. Late-onset of neonatal sepsis (LONS) is defined as the onset of symptoms after 7 days of life. Similar to the early-onset of neonatal sepsis, there is variability in LONS definition that is defined from the onset at $>72$ hours of life to $\geq 7$ days of life $(2, \underline{3})$. It is also indicated that early and late-onset of neonatal sepsis can be further categorized depending on inoculum size, neonate immunity status, and virulence of the etiologic agent (4). Neonatal factors (prematurity and low birth weight), maternal factors (maternal infections and premature rupture of membrane), and environmental factors (admission to Neonatal Intensive Care Unit (NICU), unhygienic living environment) are among the known risk factors of neonatal sepsis $(\underline{5}, \underline{6})$.

Neonatal death continued to be a global challenge though many countries have made fruitful efforts to end 
preventable neonatal death. Globally, about 2.5 million newborns are dying annually. Approximately 7000 newborns are dying every day in 2018 which represents $47 \%$ share for under-five mortality (7). The majority of this death has occurred in Sub-Saharan Africa and Southern Asian Countries (ㄱ). Neonatal prematurity, intrapartum related events (perinatal asphyxia/birth asphyxia), sepsis, and congenital malformations are among the causes of neonatal death worldwide $(\underline{8}, \underline{9})$. Most of this death can be prevented through improving quality ANC (Antenatal Care) and PNC (Postnatal Care) coverage, providing skilled care at birth, and care of small and sick babies $(\underline{7}, \underline{10})$.

There is a significant improvement in implementing maternal and newborn care services in Ethiopia since 2005. The ANC coverage was improved to $74 \%$ from $28 \%$, skilled care at birth was improved to $50 \%$ from $6 \%$, and institutional delivery was improved to $48 \%$ from 5\%. Currently, PNC for the mother and newborn is $34 \%$ (11). Furthermore, the government has paid due attention to train nurses specifically in a neonatal nursing specialty program in few Ethiopian Universities. Despite the remarkable progress the Ethiopian government has made in reducing neonatal death, neonatal mortality rate has remained stagnant. According to 2019, the Ethiopian Demographic and Health Survey (EDHS) the neonatal mortality rate in Ethiopia is 30 deaths/1000 live births, which accounts for nearly half of under-five mortality (11). Ethiopia is among one of the countries with the highest neonatal death from the world. With this regard, a greater work is waiting for Ethiopia to reduce neonatal death to fewer than 12 deaths/1000 live births to meet SDG (Sustainable Development Goal $(\underline{7}, \underline{11})$.

Evidence revealed that the prevalence of neonatal sepsis is high in Ethiopia. A systematic review in Ethiopia showed that the prevalence of neonatal sepsis was 45\% (12). Moreover, neonatal sepsis ranges from $34 \%$ to $77.9 \%$ in different parts of Oromia regional state $(13,14)$. It was the leading cause of neonatal death in Oromia Regional state as neonatal infections account for more than one-third of neonatal death in Jimma Zone $(\underline{15})$, and more than half (60\%) in Nekemte referral hospital (16). Even though the study done in Mekelle city, identified STI (Sexually transmitted infections), prolonged PROM (Premature Rupture of Membrane), intrapartum fever, and low Apgar score at 5th minute as neonatal sepsis risk factors, there is a need to conduct the study as neonatal risk factors may vary from place to place and in different contexts $(\underline{17})$.

Further improvement in ANC \& PNC coverage, compliance to infection prevention strategies, and early identification and treatment of neonatal infections, are some of the activities needed to avert neonatal death due to neonatal infections $(\underline{6}, \underline{7})$. However, in Ethiopia, the real cause and risk factors for neonatal sepsis is not well known and documented. Neonatal sepsis is the leading cause of septic shock, devastating central nerve system (CNS) consequences when involved, prolonged hospital stays, medical expenses, and even death $(\underline{17}, \underline{18})$.

In Ethiopia, particularly in the study area, the prevalence of neonatal sepsis is still high, which is among the leading cause of neonatal mortality (16). However, a very limited number of studies were conducted in Ethiopia concerning risk factors for neonatal sepsis. Therefore; this study was aimed at determining risk factors for neonatal sepsis in Public hospitals in Wollega zones, Western Ethiopia. The finding of the study will be an input for health care providers and policymakers to design interventions to avert neonatal morbidity and mortality occurring from neonatal sepsis.

\section{Methods \\ Study area, period and design}

A hospital-based unmatched case-control study was conducted in five selected public hospitals found in Wollega zones, Western Oromia Regional State, Ethiopia from October to December 2019. The largest town of Wollega zones is Nekemte town which is located 330 kilometers to the Western part from the capital city of Ethiopia, Addis Ababa. The study was undertaken in five public hospitals (Wollega University Referral Hospital, Nekemte Specialized hospital, three general hospitals (Jimma Arjo, Gimbi, and Shambu Hospitals). These hospitals were randomly selected from 11 public hospitals found in Wollega Zones.

\section{Source of population}

All newborns admitted to the neonatal intensive care unit with their index mothers were the source population of the study. In this study, cases were neonates with neonatal sepsis admitted to the neonatal intensive care unit of five selected public hospitals and fulfill the inclusion criteria. Controls were neonates without neonatal sepsis admitted to the neonatal intensive care units of the selected hospitals of the cases and fulfill the inclusion criteria.

\section{Sample size determination and sampling procedures}

The required sample size was calculated by two population proportion formulas using open Epi Info version 7. The sample size required for the study was determined by considering that $95 \%$ confidence interval (CI), $80 \%$ power of the study, and based on the study done in a specialist hospital in Ghana using neonates APGAR score at the fifth minute $14.1 \%$ among controls and $28.2 \%$ among cases, respectively, to determine case to control the ratio of $1: 1$ to detect an odds ratio of $2.39(\underline{19})$, which gave us 290 . Thus, by adding $10 \%$ for the non-response 
rate, a total sample size of 320 to include 160 cases and 160 controls in the study. Consecutive sampling technique was used to select the study participants until the required sample is obtained from the selected hospitals.

Based on the number of newborns admitted in the last three months prior to the data collection period in each hospital, totally 475 newborns were admitted to NICU in the selected public hospitals. The number of neonates admitted to Wollega University Referral Hospital, Nekemte Specialized Hospital, Gimbi, Shambu, and Jimma Arjo hospitals was 140, 130, 76, 83, and 46, respectively. Using the proportional allocation to population size, we determined the number of neonates required from Wollega University Referral Hospital (94), Nekemte Specialized Hospital (88), Gimbi (51), Shambu (56) and Jimma Arjo (31) Hospitals. Then, the number of cases and controls was allocated equally for each hospital.

\section{Data collection tools}

The data collection tool used for this study was developed after extensively reviewing literature published in reputable journals; and prepared in the English language. The data collection tool used for gathering data contains four parts: The first part of the data collection tool was socio-demographic information of the newborn's mother. The second part of the data collection tool was about maternal obstetric history. Furthermore, the third part of the data collection tool was neonatal related factors, and the fourth part of the data collection tool was a checklist for the medical record review.

\section{Data collection procedures}

Data was collected using a pretested semi-structured interviewer-administered questionnaire and checklist for the medical record review. During the medical record review, newborn gestational age, birth weight, APGAR score at the 1st and 5th minute, whether the baby (cried immediately after birth and newborn resuscitated at birth), induction performed, oxytocin given during pregnancy, newborn danger signs and hematologic values were extracted. Ten data collectors and five supervisors who were working in the selected hospitals were recruited for collecting data. The training was given for data collectors and supervisors two weeks before the actual data collection period for one day regarding the purpose of the study, on selection techniques, the study respondents, data completion, and obtaining informed consent, keeping confidentiality, respecting participants' willingness, and reviewing and recording from medical records.

\section{Data quality assurance}

Before the actual data collection, the pretest was conducted in Guduru Hospital which is found in East Wollega Zone among $5 \%(\mathrm{~N}=16)$ of the final sample size. In the pretest, the proportions of cases to controls were 1:1 (8 cases and 8 controls). Some modifications were done based on the pretest. To ensure the quality of data, the questionnaire was translated into Afaan Oromo and the respondents were interviewed in Afaan Oromo. The translation was done by language experts and investigators familiar in both Afaan Oromo and the English Language. However, the checklist based questionnaires were not translated in to the local language since data collectors are health professionals and information are also written in medical charts in English Language. The data collection tool was face validated by experienced researchers and experts of maternal and child health area.

\section{Data processing and analysis}

Data was entered, coded, and cleaned using Epi Data version 3.1 and transported to SPSS version 21 for analysis. Frequencies and percentages were calculated to all variables, the mean and standard deviation was computed for continuous variables. Multivariable logistic regression was used to determine the risk factors of neonatal sepsis. Multicollinearity was checked and variance inflation factor (VIF) was 1.03. Cross tabulation checked and reported an interaction if the $\mathrm{p}$-value for the test was $<0.05$. The goodness of fit of the model was checked using the Hosmer-Lemeshow test and is fitted well as p-value was $>0.05$. Independent risk factors for neonatal sepsis were interpreted as significant if the $p$-value is $<0.05$ in a stepwise backward multivariable logistic regression analysis.

\section{Ethical considerations}

The study was conducted after ethical clearance was obtained from Wollega University, Institute of Health Science Ethical Review Board (reference number: WU-141,699/RES1-26). A supportive letter was obtained from each respective selected hospital to collect data from the respondents. Written informed consent was obtained from each mother of the neonate. The mothers were informed that the participation is voluntary, the information they provide kept confidential and they have the right to withdraw from the study at any time during the interview. 


\section{Results}

Socio-demographic characteristics mothers

A total of 300 neonates with their index mothers were included giving a response rate of $93.75 \%$. The age of mothers range from 16 to 43 years with the mean $( \pm \mathrm{SD}) 26.26 \pm 5.04$ years, and it ranges from 16 to 43 years. Seventy-six (50.7\%) of mothers of neonates among cases and $69(46 \%)$ of mothers of neonates among controls were rural dwellers. Fifty-six (37.3\%) of mothers of neonates among cases and $120(40 \%)$ of mothers of neonates among controls did not attend their formal education (Table 1).

Table 1: Socio-demographic characteristics of mothers of the neonates admitted to NICUs of the selected public hospitals in Wollega Zones, Ethiopia, 2020

\begin{tabular}{l|l|l|l|l}
\hline Variables & Category & Cases, N (\%) & Controls, N (\%) & Total, N (\%) \\
\hline Maternal age & $15-24$ years & $59(39.3)$ & $52(34.7)$ & $111(37.0)$ \\
\hline & $25-34$ years & $71(47.4)$ & $88(58.6)$ & $159(53.0)$ \\
\hline Marital status & $\geq 35$ years & $20(13.3)$ & $10(6.7)$ & $30(10.0)$ \\
\hline & Single & $13(8.7)$ & $11(7.3)$ & $24(8.0)$ \\
\hline Religion & Married & $130(86.6)$ & $136(90.7)$ & $266(88.7)$ \\
\hline & Others ${ }^{\mathrm{a}}$ & $7(4.7)$ & $3(2.0)$ & $10(3.3)$ \\
\hline & Protestant & $105(70.0)$ & $91(60.7)$ & $196(65.3)$ \\
\hline Ethnicity & Orthodox & $26(17.4)$ & $37(24.6)$ & $63(21.0)$ \\
\hline & Muslim & $17(11.3)$ & $22(14.7)$ & $39(13.0)$ \\
\hline Residence & Others ${ }^{b}$ & $2(1.3)$ & $0(0)$ & $2(0.7)$ \\
\hline & Oromo & $139(92.7)$ & $136(90.6)$ & $275(91.7)$ \\
\hline Maternal education & Amhara & $11(7.3)$ & $13(8.7)$ & $24(8.0)$ \\
\hline & Others & $1(0.7)$ & $1(0.3)$ \\
\hline & No formal education & $37(24.7)$ & $81(54.0)$ & $155(51.7)$ \\
\hline & Able to read and write & $19(12.6)$ & $69(46.0)$ & $145(48.3)$ \\
\hline Occupation & Elementary school & $36(24.0)$ & $29(19.4)$ & $66(22.0)$ \\
\hline of mother & High school and above & $58(38.7)$ & $36(23.3)$ & $54(18.0)$ \\
\hline & House wife & $94(62.7)$ & $87(58.0)$ & $72(24.0)$ \\
\hline & Government employee & $25(16.7)$ & $20(13.3)$ & $108(36.0)$ \\
\hline & Merchant & $9(6.0)$ & $17(11.3)$ & $181(60.3)$ \\
\hline & Private organization & $13(8.7)$ & $10(6.7)$ & $26(15.0)$ \\
\hline & Daily laborer & $7(4.7)$ & $5(3.3)$ & $23(7.7)$ \\
\hline & Student & $2(1.2)$ & $11(7.3)$ & $12(4.0)$ \\
\hline & & & $13(4.3)$ \\
\hline
\end{tabular}

\section{Obstetrics characteristics of the mothers}

The number of parity ranges from 1 to 8 live births with the mean of 2.17 and standard deviation ( $\mathrm{SD} \pm$ ) of 1.53. The majority of the mothers $142(94.7 \%)$ among cases and $142(94.7 \%)$ of mothers among controls were booked for ANC service. However, 127(88.8\%) of mothers among cases and 124 (88.6\%) of mothers among controls visited the ANC clinic less than 4 times. The proportion of hospital delivery is lower among cases $99(66 \%)$ than controls 107(71.3\%). The percentage of premature rupture of membrane (PROM) among cases 39(26\%) was approximately triple of the PROM in the controls 14(9.3\%). Similarly, mothers who had experienced a prolonged premature rupture of membrane ( $>18$ hours) are more than two times in cases $37(24.7 \%)$ than controls $16(10.7 \%)$. Moreover, the proportion of mothers who had a history of either urinary tract infections or sexually transmitted infections (UTI/STI) during pregnancy was a fraction higher in the cases, 46(30.7\%), than controls, $20(13.3 \%)$ (Table 2). 
Table 2: Obstetric characteristics of the mothers of the neonates admitted to the selected public hospitals in Wollega zones, Western Ethiopia, 2020

\begin{tabular}{|c|c|c|c|c|}
\hline Variables & Category & Cases, N (\%) & Controls, N (\%) & Total, N (\%) \\
\hline \multirow[t]{2}{*}{ Parity } & $<3$ & $104(69.3)$ & $103(68.7)$ & $207(69.0)$ \\
\hline & $\geq 3$ & $46(30.7)$ & $47(31.3)$ & $93(31)$. \\
\hline \multirow[t]{2}{*}{ Booked ANC } & Yes & $142(94.7)$ & $142(94.7)$ & $284(93.7)$ \\
\hline & No & $8(5.3)$ & $8(5.3)$ & $16(6.3)$ \\
\hline \multirow[t]{2}{*}{ Time of ANC Booked } & Before or at 6 th month & $130(90.3)$ & $130(92.9)$ & $260(86.7)$ \\
\hline & After 6th month & $14(9.7)$ & $10(7.1)$ & $24(8.0)$ \\
\hline \multirow[t]{2}{*}{ Frequency of ANC visit } & $<4$ times & $127(88.8)$ & $124(88.6)$ & $251(83.7)$ \\
\hline & $\geq 4$ times & $16(11.2)$ & $16(11.4)$ & $32(10.7)$ \\
\hline \multirow[t]{3}{*}{ Place of delivery } & Home & $17(11.3)$ & $8(5.3)$ & $25(8.3)$ \\
\hline & Hospital & $99(66.0)$ & $107(71.3)$ & $206(68.7)$ \\
\hline & Health center & $34(22.7)$ & $35(23.3)$ & $69(23.0)$ \\
\hline \multirow[t]{2}{*}{ Delivery mode } & Spontaneous & $119(79.3)$ & $110(73.3)$ & $229(76.3)$ \\
\hline & Cesarean section & $31(20.7)$ & $40(26.7)$ & $71923.7)$ \\
\hline \multirow[t]{4}{*}{ Birth attendant } & TBA & $2(1.3)$ & $6(4.0)$ & $8(2.6)$ \\
\hline & HEW & $2(1.3)$ & $0(0.0)$ & $2(0.7)$ \\
\hline & $\mathrm{HCP}$ & $131(87.3)$ & $138(92.0)$ & $269(89.7)$ \\
\hline & Relative/neighbor & $15(10)$ & $6(4.0)$ & $21(7.0)$ \\
\hline \multirow[t]{3}{*}{ Labor duration } & $<6$ hours & $60(40)$ & $74(49.3)$ & $134(44.7)$ \\
\hline & 6-18 hours & $59(39.3)$ & $64(42.7)$ & $123(41.0)$ \\
\hline & $>18$ hours & $31(20.7)$ & $12(8.0)$ & $43(14.3)$ \\
\hline \multirow[t]{2}{*}{ Vaginal examination (VE) } & Yes & $128(85.3)$ & $133(88.7)$ & $261(87.0)$ \\
\hline & No & $22(14.7)$ & $17(11.3)$ & $39(13.0)$ \\
\hline \multirow[t]{2}{*}{ Frequency of VE } & $<6$ times & $113(88.3)$ & $126(93.3)$ & $239(79.7)$ \\
\hline & $\geq 6$ times & $15(11.7)$ & $9(6.7)$ & $24(8.0)$ \\
\hline \multirow[t]{2}{*}{ PROM } & Yes & $39(26.0)$ & $14(9.3)$ & $53(17.7)$ \\
\hline & No & $111(74.0)$ & $136(90.7)$ & $247(82.3)$ \\
\hline \multirow[t]{2}{*}{ Prolonged ROM >18hours } & Yes & $37(24.7)$ & $16(10.7)$ & $53(17.7)$ \\
\hline & No & $113(75.3)$ & $134(89.3)$ & $247(82.3)$ \\
\hline \multirow[t]{2}{*}{ Preterm PROM } & Yes & $13(8.7)$ & $15(10.0)$ & $28(9.3)$ \\
\hline & No & $136(91.3)$ & $135(90.0)$ & $271(90.3)$ \\
\hline \multirow[t]{2}{*}{ Intrapartum fever } & Yes & $39(26.0)$ & $18(12.0)$ & $57(19.0)$ \\
\hline & No & $111(74.0)$ & $132(88.0)$ & $243(81.0)$ \\
\hline \multirow[t]{2}{*}{ Foully smelling liquor } & Yes & $26(17.3)$ & $8(5.3)$ & $34(11.3)$ \\
\hline & No & $124(82.7)$ & $142(94.7)$ & $266(88.7)$ \\
\hline \multirow[t]{2}{*}{ Hypertension } & Yes & $14(9.3)$ & $10(6.7)$ & $24(8.0)$ \\
\hline & No & $136(90.7)$ & $140(93.3)$ & $276(92.0)$ \\
\hline \multirow[t]{2}{*}{ Diabetes mellitus } & Yes & $1(0.7)$ & $2(1.3)$ & $3(1.0)$ \\
\hline & No & $149(99.3)$ & $148(98.7)$ & $297(99.0)$ \\
\hline \multirow[t]{2}{*}{ STI/UTI history } & Yes & $46(30.7)$ & $20(13.3)$ & $66(22.0)$ \\
\hline & No & $104(69.3)$ & $130(86.7)$ & $234(78.0)$ \\
\hline
\end{tabular}

\section{Characteristics of neonates admitted to NICUs}

The mean and $( \pm \mathrm{SD})$ of age of the neonates was 5.56 and \pm 5.46 , respectively. Among male neonates, $83(55.3 \%)$ had neonatal sepsis, meanwhile, $93(62 \%)$ of female neonates had not had neonatal sepsis. One hundred nine $(72.7 \%)$ of cases and $106(70.7 \%)$ of controls were delivered between gestational ages of 37-42 weeks. More than half, $183(61 \%)$ of the neonates included in the study had a normal birth weight 2500-3999 grams. The proportion of neonates who had an Apgar score $<7$ at the 1 st minute was higher among cases, $132(96.4 \%)$ than $118(80.8 \%$, controls. Even though $201(67 \%)$ of neonates cried immediately after birth, the fraction of neonates among cases 81(54\%) were lower than controls 120 (80\%). Similarly, $86(57.3 \%)$ of neonates among cases and $48(32 \%)$ among controls were resuscitated at birth (Table 3$)$. 
Table 3: Neonatal characteristics admitted to NICUs of the selected public hospitals in Wollega zones, Western Ethiopia, 2020

\begin{tabular}{|c|c|c|c|c|}
\hline Variables & Category & Cases, N (\%) & Controls, N (\%) & Total, N (\%) \\
\hline \multirow[t]{2}{*}{ Neonate's age(days) } & $>7$ & $117(78.0)$ & $124(82.7)$ & $241(80.3)$ \\
\hline & $\geq 7$ & $33(22.0)$ & $26(17.3)$ & $59(19.7)$ \\
\hline \multirow[t]{2}{*}{ Neonate's sex } & Male & $83(55.3)$ & $93(62.0)$ & $176(58.7)$ \\
\hline & Female & $67(44.7)$ & $57(38.0)$ & $124(41.3)$ \\
\hline \multirow[t]{3}{*}{ Gestational age } & 28-32weeks & $10(6.7)$ & $8(5.3)$ & $18(6.0)$ \\
\hline & 34-36 weeks & $31(20.7)$ & $36(24.0)$ & $67(22.3)$ \\
\hline & $\geq 37$ weeks & $109(72.7)$ & $106(70.7)$ & $215(71.7)$ \\
\hline \multirow[t]{3}{*}{ Birth weight (gram) } & $1000-2499$ & $54(36.0)$ & $49(32.7)$ & $103(34.3)$ \\
\hline & $2500-3999$ & $88(58.7)$ & $95(63.3)$ & $183(61.0)$ \\
\hline & $\geq 4000$ & $8(5.3)$ & $6(4.0)$ & $14(4.7)$ \\
\hline \multirow[t]{2}{*}{$1^{\text {st }}$ minute APGAR score } & $<7$ & $132(96.4)$ & $118(80.8)$ & $250(83.3)$ \\
\hline & $\geq 7$ & $5(3.6)$ & $28(19.2)$ & $33(11.0)$ \\
\hline \multirow[t]{2}{*}{$5^{\text {th }}$ minute APGAR score } & $<7$ & $105(76.6)$ & $54(37.0)$ & $159(53.0)$ \\
\hline & $\geq 7$ & $32(23.4)$ & $92(63.0)$ & $124(41.3)$ \\
\hline \multirow[t]{2}{*}{ Baby cried immediately after birth } & Yes & $81(54.0)$ & $120(80.0)$ & $201(67.0)$ \\
\hline & No & $69(46.0)$ & $30(20.0)$ & $99(33.0)$ \\
\hline \multirow[t]{2}{*}{ Resuscitated at birth } & Yes & $86(57.3)$ & $48(32.0)$ & $134(44.7)$ \\
\hline & No & $64(42.7)$ & $102(68.0)$ & $166(55.3)$ \\
\hline \multirow[t]{2}{*}{ Meconium staining } & Yes & $32(21.3)$ & $26(17.3)$ & $58(19.3)$ \\
\hline & No & $118(78.7)$ & $124(82.7)$ & $242(80.7)$ \\
\hline \multirow[t]{2}{*}{ Induction performed } & Yes & $33(22.0)$ & $25(16.7)$ & $58(19.3)$ \\
\hline & No & $117(78.0)$ & $125(83.3)$ & $242(80.7)$ \\
\hline \multirow[t]{2}{*}{ Oxytocin given } & Yes & $41(27.3)$ & $27(18.0)$ & $68(22.7)$ \\
\hline & No & $109(72.7)$ & $123(82.0)$ & $232(77.3)$ \\
\hline
\end{tabular}

a: Widowed and divorced; b: Catholic; c: Guraghe

Risk factors of neonatal sepsis for neonates admitted to NICU

The analysis showed that mothers who experienced the premature rupture of the membrane, maternal history of UTI/STI, APGAR score less than 7 at the $5^{\text {th }}$ minute, and neonate resuscitated at birth were significantly with the neonatal sepsis.

Accordingly, the odds of neonatal sepsis among mothers who had PROM were 2.94 times higher than mothers who had no PROM [AOR=2.9, 95\% CI (1.39-6.06)]. It is also shown that neonates born to mothers who had UTI/STI during the index pregnancy were 2.11 times more likely to develop sepsis compared to neonates born to mothers who did not have a history of UTI/STI during their pregnancy period $[\mathrm{AOR}=2.11,95 \% \mathrm{CI}$ (1.06-4.19)]. Similarly, the study found the likelihood of developing neonatal sepsis was 3.69 times higher among neonates with Apgar scores of $<7$ than neonates who had an Apgar score $>=7$ at the fifth minute $[\mathrm{AOR}=3.69,95 \% \mathrm{CI}(2.08-6.53)]$. Additionally, it is indicated that neonates who resuscitated at birth were 2.93 times more likely to develop sepsis compared to neonates who did not resuscitate at birth $[\mathrm{AOR}=2.93,95 \% \mathrm{CI}$ (1.67-5.14)] (Table 4). 
Table 4: Bi-variable and multivariable analysis of risk factors for neonatal sepsis admitted to NICUs of the selected public hospitals in Wollega zones, Western Ethiopia, 2020

\begin{tabular}{|c|c|c|c|c|c|}
\hline \multirow[t]{2}{*}{ Variables } & \multirow[t]{2}{*}{ Category } & \multirow{2}{*}{$\begin{array}{ll}\begin{array}{l}\text { Cases, } \\
(\%)\end{array} & \mathbf{N} \\
(\%)\end{array}$} & \multirow{2}{*}{$\begin{array}{l}\text { Controls, } \\
\text { N (\%) }\end{array}$} & \multicolumn{2}{|c|}{ OR [95\%CI] } \\
\hline & & & & COR & AOR \\
\hline \multirow[t]{3}{*}{ Maternal age } & $15-24$ years & $59(39.3)$ & $52(34.7)$ & 1 & 1 \\
\hline & $25-34$ years & $71(47.4)$ & $88(58.7)$ & $0.57(0.24-1.32$ & $1.5(0.50-4.47)$ \\
\hline & $\geq 35$ years & $20(13.3)$ & $10(6.7)$ & $0.4(0.18-0.91)$ & $0.8(0.28-2.27)$ \\
\hline \multirow[t]{2}{*}{ PROM } & Yes & $39(26.0)$ & $14(9.3)$ & $3.41(1.76-6.60)$ & $2.9(1.39-6.06)^{*}$ \\
\hline & No & $111(74.0)$ & $136(90.7)$ & 1 & 1 \\
\hline \multirow{2}{*}{$\begin{array}{l}\text { Prolonged } \\
\text { ROM >18hours } \\
\end{array}$} & Yes & $37(24.7)$ & $16(10.7)$ & $2.74(1.45-5.18)$ & $1.78(0.81-3.89)$ \\
\hline & No & $113(75.3)$ & $134(89.3)$ & 1 & 1 \\
\hline \multirow[t]{2}{*}{ Intrapartum fever } & Yes & $39(26.0)$ & $18(12.0)$ & $2.57(1.39-4.75)$ & $0.86(0.39-1.90)$ \\
\hline & No & $111(74.0)$ & $132(88.0)$ & 1 & 1 \\
\hline \multirow[t]{2}{*}{ Foully smelling liquor } & Yes & $26(17.3)$ & $8(5.3)$ & $3.72(1.62-8.52)$ & $1.56(0.57-4.24)$ \\
\hline & No & $124(82.7)$ & $142(94.7)$ & 1 & 1 \\
\hline \multirow[t]{2}{*}{ STI/UTI } & Yes & $46(30.7)$ & $20(13.3)$ & $2.88(1.60-5.16)$ & $2.11(1.06-4.19)$ \\
\hline & No & $104(69.3)$ & $130(86.7)$ & 1 & 1 \\
\hline \multirow{2}{*}{$\begin{array}{l}1^{\text {st }} \text { minute APGAR } \\
\text { score }\end{array}$} & $<7$ & $132(96.4)$ & $118(80.8)$ & $6.26(2.34-16.7)$ & $2.01(0.64-6.34)$ \\
\hline & $\geq 7$ & $5(3.6)$ & $28(19.2)$ & 1 & 1 \\
\hline \multirow{2}{*}{$\begin{array}{l}5^{\text {th }} \text { minute } \text { APGAR } \\
\text { score }\end{array}$} & $<7$ & $105(76.6)$ & $54(37.0)$ & $5.59(3.32-9.39)$ & $3.69(2.08-6.53)^{*}$ \\
\hline & $\geq 7$ & $32(23.4)$ & $92(63.0)$ & 1 & 1 \\
\hline \multirow{2}{*}{$\begin{array}{l}\text { Baby cried } \\
\text { immediately after birth }\end{array}$} & Yes & $81(54.0)$ & $120(80.0)$ & $0.29(0.17-0.49)$ & $0.94(0.43-2.04)$ \\
\hline & No & $69(46.0)$ & $30(20.0)$ & 1 & 1 \\
\hline \multirow[t]{2}{*}{ Resuscitated at birth } & Yes & $86(57.3)$ & $48(32.0)$ & $2.85(1.78-4.57)$ & $2.93(1.67-5.14)^{*}$ \\
\hline & No & $64(42.7)$ & $102(68.0)$ & 1 & 1 \\
\hline \multirow[t]{2}{*}{ Induction performed } & Yes & $33(22.0)$ & $25(16.7)$ & $1.41(0.79-2.51)$ & $0.94(0.45-1.98)$ \\
\hline & No & $117(78.0)$ & $125(83.3)$ & 1 & 1 \\
\hline
\end{tabular}

\section{Discussion}

Neonatal infection is among the leading cause of neonatal morbidity and mortality in Ethiopia. Even though several studies conducted on prevalence of neonatal sepsis, there are very limited studies on identifying its risk factors in Ethiopia, particularly in the study area. Hence, this study aimed at determining risk factors for neonatal sepsis among neonates admitted to NICU of public hospitals of Wollega zones. This helps in identifying the specific risk factors and take appropriate interventions to reduce the progress of neonatal sepsis that results in morbidity and mortality. The findings showed that PROM, maternal history of UTI/STI, APGAR scores $<7$ at the $5^{\text {th }}$ minute, and baby resuscitation at birth were the independent significant risk factors for neonatal sepsis.

Our analysis realized that more than three-fourth of the cases $(78.7 \%)$ had early onset of neonatal sepsis $(<$ 7 days). This is slightly higher compared to the study findings undertaken in our country (Ethiopia): in Mekelle City (76.9\%) which may be due to a slightly higher number of preterm babies included in the current study. Preterm babies are at particular risk of early neonatal infection due to their immature immunity and invasive procedures to which they are subjected. It is lower compared to finding from Bishoftu (81.4\%), this might be as a result of a relatively higher number under 7 days old infants were included in the study done in Bishoftu. However, it is similar to a study done in Ghana $(78.7 \%)(\underline{17}, \underline{20}, \underline{21})$.

Also, this study revealed that the odds of having a newborn with sepsis were almost 3 times higher among mothers who had experienced a premature rupture of the membrane than their counterparts. This is in harmony with the other study findings from Debremarkos referral hospital, Gheam hospital of Iran, tertiary care hospital of Pakistan, and India (22-24). This is maybe due to the premature rupture of the membrane that can lead to chorioamnionitis (intrauterine infection) either due to ascending infection or repeated digital examination.

In this study, the odds of having a baby with neonatal sepsis were 2.11 times higher among mothers who had UTI/STI during pregnancy than their counterparts. This is supported by the study done in Mekelle city, Bishoftu, India, and Ghana $(\underline{17}, \underline{20}, \underline{21})$. This is since maternal urinary tract infections can cause neonatal sepsis through vertical transmission of pathogenic organisms from the genital tract. Moreover, the maternal heavy burden of GBS colonization indicates a notable risk for the acquisition of neonatal GBS infection from the maternal genital tract (4). Moreover, a presence of discharge from the maternal genital tract or open skin around 
the maternal genital area helps the microorganisms' multiplication and causes an ascending infection that can cause neonatal sepsis.

Furthermore, the present study revealed that the odds of developing neonatal sepsis was 3.76 times higher among neonates with Apgar scores of $<7$ compared to neonates who had an Apgar score $\geq 7$ in the fifth minute. Findings from previous studies conducted in Bangladesh (2011), Ghana (2014), and Ethiopia in Mekelle city (2016) have also found consistent findings $(\underline{17}, \underline{20}, \underline{25})$. This describes that neonatal resuscitation may expose newborns to pathogenic microbes as newborns with APGAR score of less than 7 may require resuscitation to sustain life (25). Besides, it implies health professionals who conduct neonatal resuscitation may not use the sterile resuscitating equipment to avoid the possible sources of infection during the neonatal resuscitation procedure.

The current study analysis also showed that neonatal resuscitation at birth was associated with an almost three-fold increase $(\mathrm{OR}=2.93)$ in the risk of neonatal sepsis. This evidence is in line with the previous study in rural Ghana (20). Studies suggested resuscitation at birth is associated with an increased risk of bacterial infection which might be due to exposure to microbes during the resuscitation procedures (26). Instrumentations are long-established risk factors for sepsis among clients with a weak immunity (hospitalized patients, neonates, and the elderly) (27). This can happen either by utilization of unsterile resuscitating equipment or unclean procedures of newborn resuscitation.

Literature found maternal age, prolonged rupture of membrane, intrapartum fever, and foul-smelling liquor, multiple vaginal examinations, prematurity, and low birth weight as independent predictors of neonatal sepsis $(\underline{20}, \underline{25})$. Despite available pieces of evidence suggested maternal age, place of residence, educational level, parity, ANC service utilization, mode of delivery, prolonged rupture of membrane, foul-smelling liquor, neonatal sex, neonatal age, and baby crying after birth as an independent predictor of neonatal sepsis, all of them showed no statistically significant association with neonatal sepsis in the current study $(\underline{17}, \underline{20}, \underline{21})$. This might be a variation in sample size among studies or differences among the study population.

\section{Limitation of the study}

Since the study employed the consecutive sampling technique, generalizing the finding to the source population might be difficult. Besides, laboratory hematologic tests have limited diagnostic accuracy compared to culture test or other microbiology tests as the neonatal sepsis were diagnosed based on the hematologic and clinical signs. Moreover, the study did not assess environmental factors for neonatal sepsis.

\section{Conclusion}

Generally, the present study showed that the premature rupture of the membrane, UTI/STI history, neonate resituated at birth and who had low APGAR score at the fifth minute as independent risk factors of the neonatal sepsis. There is a need to improve maternal awareness regarding the consequences of the premature rupture of the membrane, and sexually transmitted/urinary tract infections on the neonate. Furthermore, early identification and prompt management of maternal urinary tract infections/sexually transmitted infections during antenatal care service should be emphasized. Also, enhancing safe neonatal resuscitation and infection prevention practice of delivery unit staff through provision of refreshment course.

\section{Abbreviations}

EONS: Early onset neonatal sepsis, LONS: late onset neonatal sepsis, UN IGME: The United Nations Interagency Group for Child Mortality Estimation, NMR: Neonatal Mortality Rate, EDHS: Ethiopian Demographic and Health Survey, GBS: Group B Streptococcus, WHO: World Health Organization, ANC: Antenatal care, IMNCI: Integrated Management of Neonatal and Childhood Illness, ESR: Erythrocyte Sedimentation Rate, NICU: Neonatal Intensive Care Unit, PROM: Premature Rupture Of Membrane, ROM: Rupture of membrane, STI: Sexually transmitted infections, UTI: Urinary Tract Infections.

\section{Acknowledgment}

Our sincere gratitude goes to data collectors, supervisors and the study participants for their contribution of this research. We also each hospital medical directors for their kind support during the study period.

\section{References}

1. Ethiopian Federal Ministry of Health, EFMOH: Management Protocol of Neonatal Intensive Care Unit (NICU)Training manual. November,2014.

2. Rao SC, Srinivasjois R, Moon K. One dose per day compared to multiple doses per day of gentamicin for treatment of suspected or proven sepsis in neonates. The Cochrane database of systematic reviews. 2016;12(12):Cd005091.

3. American Academy of Pediatrics. Group B streptococcal infections. In: Red Book: 2018 Report of the 
Committee on Infectious Diseases, 31st ed, Kimberlin DW, Brady MT, Jackson MA, Long SS (Eds), American Academy of Pediatrics, Itasca, IL 2018. p.762.

4. Shane AL, Sánchez PJ, Stoll BJ. Neonatal sepsis. The Lancet. 2017;390(10104):1770-80.

5. Camacho-Gonzalez A, Spearman PW, Stoll BJ. Neonatal infectious diseases: evaluation of neonatal sepsis. Pediatric Clinics of North America. 2013;60(2):367.

6. Satar M, Özlü F. Neonatal sepsis: a continuing disease burden. The Turkish journal of pediatrics. 2012;54(5):449.

7. United Nations Inter-agency Group for Child Mortality Estimation (UNIGME), 'Levels \& Trends in Child Mortality: Report 2019, Estimates developed by the United Nations Inter-agency Group for Child Mortality Estimation', United Nations Children's Fund, New York, 2019.

8. MCEE W. MCEE-WHO methods and data sources for child causes of death 2000-2015. World Health Organization. 2016.

9. Lawn JE, Cousens S, Zupan J, Team LNSS. 4 million neonatal deaths: when? Where? Why? The lancet. 2005;365(9462):891-900.

10. Lawn JE, Mwansa-Kambafwile J, Horta BL, Barros FC, Cousens S. 'Kangaroo mother care'to prevent neonatal deaths due to preterm birth complications. International journal of epidemiology. 2010;39(suppl 1):i144-i54.

11. Ethiopian Public Health Institute (EPHI) [Ethiopia] and ICF. 2019. Ethiopia Mini Demographic and Health Survey 2019: Key Indicators. Rockville, Maryland, USA: EPHI and ICF.

12. Assemie MA, Alene M, Yismaw L, Ketema DB, Lamore Y, Petrucka P, et al. Prevalence of Neonatal Sepsis in Ethiopia: A Systematic Review and Meta-Analysis. International Journal of Pediatrics. 2020;2020.

13. Getabelew A, Aman M, Fantaye E, Yeheyis T. Prevalence of neonatal sepsis and associated factors among neonates in neonatal intensive care unit at selected governmental hospitals in Shashemene Town, Oromia Regional State, Ethiopia, 2017. International journal of pediatrics. 2018;2018.

14. Sorsa A. Epidemiology of neonatal sepsis and associated factors implicated: observational study at neonatal intensive care unit of Arsi University Teaching and Referral Hospital, South East Ethiopia. Ethiopian journal of health sciences. 2019;29(3).

15. Debelew GT, Afework MF, Yalew AW. Determinants and causes of neonatal mortality in Jimma zone, southwest Ethiopia: a multilevel analysis of prospective follow up study. PloS one. 2014;9(9):e107184.

16. Roro EM, Tumtu MI, Gebre DS. Predictors, causes, and trends of neonatal mortality at Nekemte Referral Hospital, east Wollega Zone, western Ethiopia (2010-2014). Retrospective cohort study. PloS one. 2019;14(10).

17. Gebremedhin D, Berhe H, Gebrekirstos K. Risk factors for neonatal sepsis in public hospitals of Mekelle City, North Ethiopia, 2015: unmatched case control study. PloS one. 2016;11(5).

18. Fuchs A, Bielicki J, Mathur S, Sharland M, Anker VD, N J. Reviewing the WHO guidelines for antibiotic use for sepsis in neonates and children. Paediatrics and international child health. 2018;38(sup1):S3-S15.

19. Adatara P, Afaya A, Salia SM, Afaya RA, Konlan KD, Agyabeng-Fandoh E, et al. Risk factors associated with neonatal sepsis: a case study at a specialist hospital in Ghana. The Scientific World Journal. 2019;2019.

20. Siakwa M, Kpikpitse D, Mupepi SC, Semuatu M. Neonatal sepsis in rural Ghana: A case control study of risk factors in a birth cohort. 2014.

21. Woldu M, Guta M, Lenjisa J, Tegegne G, Tesafye G, Dinsa H. Assessment of the incidence of neonatal sepsis, its risk factors, antimicrobial use and clinical outcomes in Bishoftu General Hospital. Neonatal Intensive Care Unit, Debrezeit-Ethiopia Pediat Therapeut. 2014;4(214):2161-0665.1000214.

22. Alam MM, Saleem AF, Shaikh AS, Munir O, Qadir M. Neonatal sepsis following prolonged rupture of membranes in a tertiary care hospital in Karachi, Pakistan. The Journal of Infection in Developing Countries. 2014;8(01):067-73.

23. Boskabadi H, Maamouri G, Mafinejad S. Neonatal complications related with prolonged rupture of membranes. Macedonian Journal of Medical Sciences. 2011;4(1):93-8.

24. Murthy S, Godinho MA, Guddattu V, Lewis LES, Nair NS. Risk factors of neonatal sepsis in India: A systematic review and meta-analysis. PloS one. 2019;14(4).

25. Hasan M, Mahmood C. Predictive values of risk factors in neonatal sepsis. Journal of Bangladesh College of Physicians and Surgeons. 2011;29(4):187-95.

26. Mansori K, Hanis SM, Shadmani FK. Postpartum modern contraceptive use in northern Ethiopia: prevalence and associated factors-methodological issues in this cross-sectional study. Epidemiology and health. 2017;39.

27. Leal YA, Álvarez-Nemegyei J, Velázquez JR, Rosado-Quiab U, Diego-Rodríguez N, Paz-Baeza E, et al. Risk factors and prognosis for neonatal sepsis in southeastern Mexico: analysis of a four-year historic cohort follow-up. BMC Pregnancy and Childbirth. 2012;12(1):48. 